\title{
AVALIAÇÃO TECNOLÓGICA, MICROBIOLÓGICA, QUÍMICA E FÍSICA DE CONSERVAS DE MEXILHÕES (Perna perna) EMBALADAS A VÁCUO
}

\author{
PAULA DE SOUZA SOMBRIO* \\ ELANE SCHWINDEN PRUDÊNCIO** \\ RENATA DIAS DE MELLO CASTANHO AMBONI ${ }^{* * *}$ \\ PEDRO LUIZ MANIQUE BARRETO**** \\ EDNAREGINA AMANTE ${ }^{\star \star \star \star \star ~}$
}

\begin{abstract}
O objetivo deste trabalho foi avaliar o efeito do processamento térmico sobre as propriedades de mexilhões em embalagem flexível a vácuo, preparados com diferentes teores de cloreto de sódio (sal) e ácido lático, mantidos a $25 \pm 1^{\circ} \mathrm{C}$ por até 90 dias. As conservas foram avaliadas quanto às características microbiológicas, $\mathrm{pH}$, bases voláteis totais (N-BVT) e perfil de textura. Essa forma de conservação mostrou-se eficiente quanto às características microbiológicas. Os resultados obtidos para coliformes a $45^{\circ} \mathrm{C}$, Salmonella ssp. e Staphylococcus coagulase positiva foram $<3 \mathrm{NMP} / \mathrm{g}$, ausência e < $10 \mathrm{UFC} / \mathrm{g}$, respectivamente. O mesmo comportamento foi observado para os teores de $\mathrm{N}$ BVT das conservas sendo todos $\leq 13,36 \mathrm{mg} / 100 \mathrm{~g}$ do produto. Valores adequados de $\mathrm{pH}(\leq 4,5)$ foram observados quando empregados teores de ácido lático entre 5,0 e 7,5\%. O teste de compressão evidenciou maior dureza e consistência nas conservas de mexilhões, armazenadas por 30 dias, quando continham menores teores de sal e maiores de ácido lático. Porém, o mesmo teste quando realizado aos 90 dias de armazenamento indicou menor dureza e consistência para conservas com maiores teores de ácido lático. No teste de penetração não foram observadas relações entre os parâmetros dureza e consistência com os teores de sal e ácido lático empregados.
\end{abstract}

PALAVRAS-CHAVE: MEXILHÕES; MICROBIOLOGIA; ANÁLISES FÍSICO-QUÍMICAS; TEXTURA.

* Química, Mestre em Engenharia de Alimentos, Departamento de Engenharia de Alimentos, Universidade Federal de Santa Catarina (UFSC), Florianópolis, Santa Catarina, Brasil (e-mail: paulasombrio@hotmail.com).

** Engenheira de Alimentos, Doutora em Ciência dos Alimentos, Professora do Departamento de Ciência e Tecnologia de Alimentos, UFSC, Florianópolis, SC, Brasil (e-mail:elane@cca.ufsc.br).

*** Engenheira de Alimentos, Doutora em Química, Professora do Departamento de Ciência e Tecnologia de Alimentos, UFSC, Florianópolis, SC, Brasil (e-mail: ramboni@cca.ufsc.br).

*** Farmacêutico, Técnico de Alimentos, Doutor em Química, Professor, Departamento de Ciência e Tecnologia de Alimentos, UFSC, Florianópolis, SC, Brasil (e-mail: barreto@cca.ufsc.br).

**** Química Industrial, Doutora em Engenharia de Produção, Professora, Departamento de Ciência e Tecnologia de Alimentos, UFSC, Itacorubi, Florianópolis, SC, Brasil (e-mail: eamante@cca.ufsc.br). 


\section{INTRODUÇÃO}

Consumida nas regiões litorâneas, a carne de mexilhões contém 15\% de proteínas de alta qualidade (WILHELM FILHO et al., 2001; HUBER, SOARES e LAURINDO, 2003; BISPO et al., 2004), sendo fonte do ácido graxo ômega-3 e de ferro. Além disso, apresenta sais minerais como cálcio, potássio, zinco, cobre, fósforo, magnésio e iodo e vitaminas B1, B2, C e PP. O consumo desse tipo de carne tem sido motivado também pelo baixo valor calórico (63 kcal/100 g do produto) e lipídico (2,3 g/100 g do produto) (SANTOS, 1982).

O cultivo de moluscos filtradores em águas brasileiras é incentivado devido à existência de locais apropriados, como as baías (FRANCO et al., 2006). A partir da década de 90 observou-se aumento abrupto no cultivo do mexilhão Perna perna, elevando o Brasil à segunda colocação entre os produtores Latino-Americanos. O Estado de Santa Catarina destaca-se como o maior produtor nacional de mexilhões, fato creditado às condições ambientais (MARENZI e BRANCO, 2005) e sociais, sendo meio de subsistência para as comunidades de maricultores (FRANCO et al., 2006). Como a industrialização de mexilhões ainda não é realidade no Estado de Santa Catarina sua comercialização ocorre de forma artesanal. Prevalece o produto in natura ou desconchado, vendido a granel ou em sacos plásticos (PACHECO, 2004).

A agregação de valor aos produtos da piscicultura está diretamente ligada à qualidade da matériaprima e ao processamento empregado, visando conservar ao máximo suas qualidades microbiológicas, químicas e sensoriais (NEIVA, 2003). Algumas alternativas para a conservação dos mexilhões são sugeridas como, por exemplo, o enlatamento (MARQUES, 1998), a refrigeração, o congelamento (BEIRÃO, TEIXEIRA e MEINERT, 2000) e a cocção seguida de congelamento (CORDEIRO, 2005).

As conservas de mexilhões são produtos simples e facilmente adaptáveis à realidade dos pequenos produtores, sendo importante alternativa de renda e oferta de novos produtos. Portanto, o objetivo deste trabalho foi avaliar a viabilidade tecnológica, microbiológica, química e física de mexilhões (Perna perna) acondicionados em embalagem flexível a vácuo e armazenados em temperatura ambiente.

\section{MATERIAL E MÉTODOS}

\subsection{MATERIAL}

Os mexilhões (Perna perna) foram coletados em área de cultivo localizada no município de Florianópolis, Estado de Santa Catarina, e transportados vivos ao laboratório. Conforme metodologia tradicional, os mexilões foram cozidos até a abertura das conchas, removidos com facas e então armazenados sob refrigeração até a elaboração das conservas. Utilizaram-se ácido lático e cloreto de sódio comerciais no preparo das conservas, sendo os reagentes empregados de grau analítico. Todas as soluções e meios de cultura foram devidamente preparados e quando necessário as soluções foram padronizadas.

\subsection{ELABORAÇÃO DAS CONSERVAS}

Foram elaborados nove tipos de conservas, contendo cerca de $200 \mathrm{~g}$ de mexilhões cada, variandose a composição dos líquidos de cobertura (Tabela 1). As quantidades dos ingredientes do líquido de cobertura foram definidas a partir de testes preliminares. Os mexilhões permaneceram em contato com o líquido de cobertura durante 30 minutos. Após drenagem, foram acondicionados em embalagens plásticas flexíveis (Cryovac ${ }^{\circledast}$ modelo C-5045) com barreira total de oxigênio, seladas a vácuo (Selovac ${ }^{\circledR}$ ), imersas em água em ebulição por 30 minutos, resfriadas e mantidas por 90 dias em temperatura ambiente $\left(25 \pm 1^{\circ} \mathrm{C}\right)$. O experimento foi realizado em duplicata. 


\section{QUANTIDADES (g/100 mL)}

\begin{tabular}{lll}
\hline 1 & 0,2 & \\
2 & 0,5 & 2,5 \\
3 & 1,0 & 2,5 \\
4 & 0,2 & 2,5 \\
5 & 0,5 & 5,0 \\
6 & 1,0 & 5,0 \\
7 & 0,2 & 5,0 \\
8 & 0,5 & 7,5 \\
9 & 1,0 & 7,5 \\
\end{tabular}

\subsection{ANÁLISE MICROBIOLÓGICA}

Determinaram-se as características microbiológicas dos mexilhões pré-cozidos e das conservas com 90 dias de armazenagem em temperatura ambiente $\left(25 \pm 1^{\circ} \mathrm{C}\right)$, mediante análises de coliformes a $45^{\circ} \mathrm{C}$, Salmonella spp. e Staphylococcus coagulase positiva (APHA, 2001). Todas as análises foram realizadas em triplicata.

\subsection{ANÁLISE QUÍMICA}

As análises de pH foram realizadas no líquido de cobertura antes da adição dos mexilhões, após 30 minutos da incorporação dos mexilhões, mas antes do tratamento térmico. Também foram efetuadas aos 30, 60 e 90 dias de armazenagem das conservas de mexilhões, termicamente tratadas, e mantidas em temperatura ambiente $\left(25 \pm 1^{\circ} \mathrm{C}\right)$. A fim de avaliar as características químicas e a eficiência do armazenamento determinaram-se os teores de Nitrogênio das Bases Voláteis Totais ( $\mathrm{N}$ BVT) nas conservas com 90 dias, conforme a metodologia descrita pelo LANARA (BRASIL, 1981). Todas estas análises foram realizadas em triplicata.

\subsection{ANÁLISE FÍSICA}

Amostras de mexilhões pré-cozidos e as conservas com 30 e 90 dias de armazenagem foram submetidas à análise instrumental do perfil de textura em texturômetro (Stevens modelo LFRA), sendo os dados adquiridos pelo software Interface ${ }^{\oplus}$. Realizou-se o teste de compressão com sensor cilíndrico de acrílico (3,75 cm de diâmetro) e o teste de penetração com sensor de aço inoxidável (5,00 mm de diâmetro), obtendo-se os parâmetros de dureza e consistência conforme AHMED et al. (2005) e HUIDOBRO et al. (2005). Os valores encontrados foram comparados com os da amostra pré-cozida, denominada de padrão, visando observar a influência do tempo de armazenamento sobre suas características físicas. Para cada teste foram realizadas cinco repetições. 


\subsection{ANÁLISE ESTATÍSTICA}

Os resultados das análises foram avaliados por meio do sistema estatístico SAS (Statistical Analysis System), versão 6.12 para Microsoft Windows (SAS, 1996), com 5\% de significância. Os resultados referentes à análise instrumental do perfil de textura foram submetidos ao teste $t$-Student (GOMES, 1990).

\section{RESULTADOS E DISCUSSÃO}

\subsection{ANÁLISE MICROBIOLÓGICA}

Os resultados das determinações de coliformes a $45^{\circ} \mathrm{C}(<3 \mathrm{NMP} / \mathrm{g})$, Salmonella ssp. (ausente) e Staphylococcus coagulase positiva ( $<10 \mathrm{UFC/g}$ ) para as nove conservas de mexilhões, armazenadas em temperatura ambiente $\left(25 \pm 1^{\circ} \mathrm{C}\right)$ por 90 dias, enquadraram-se nos limites estabelecidos pela RDC $N^{\circ} 12$, do Ministério da Agricultura (BRASIL, 2001). Os produtos em conserva obtidos não diferiram $(p<0,05)$ quanto aos resultados de coliformes a $45^{\circ} \mathrm{C}$, Salmonella ssp e Staphylococcus coagulase positiva (menores do que $3 \mathrm{NMP} / \mathrm{g}$, ausente e, menores do que $10 \mathrm{UFC} / \mathrm{g}$, respectivamente). Resultados diferentes foram obtidos por PEREIRA et al. (2004) que encontraram Aeromonas spp. em mexilhões, provenientes do município de Niterói no Estado do Rio de Janeiro, submetidos a pré-cozimento. KILINC e CAKLI (2004) obtiveram resultados semelhantes aos determinados no presente trabalho para filés de sardinha marinados. É extremamente importante conhecer as características microbiológicas dos mexilhões, pois sendo organismos filtradores podem ultrapassar facilmente os limites microbiológicos fixados pela legislação (LIZÁRRAGA-PARTIDA e CÁRDENAS, 1996). SOLIC et al. (1999) e PEREIRA et al. (2004) afirmaram que a contaminação inicial de mexilhões resulta também em produtos contaminados, mesmo quando submetidos aos processos de conservação. Essa contaminação, muitas vezes, não é eliminada por simples processos de conservação (MANOUSARIDIS et al., 2005).

\subsection{ANÁLISE QUÍMICA}

Os resultados para os valores do $\mathrm{pH}$ podem ser visualizados na Tabela 2. Maiores teores de ácido lático empregados no líquido de cobertura resultaram em menores valores para o $\mathrm{pH}$, enquanto a incorporação dos mexilhões ao líquido de cobertura elevou esses valores. Porém, as conservas avaliadas apresentaram aumento nos valores de pH após 30 dias de armazenamento. Resultados similares foram encontrados por GÖKOLU, CENGIZ e YERLIKAYA (2004), que obtiveram aumento do pH (entre 3,9 e 4,0) em anchovas marinadas contendo solução de ácido acético a 4\%. KILINC e CAKLI (2004) também confirmaram tendência de elevação nos valores do pH de pescados no período inicial de armazenamento. Segundo RUIZ-CAPILLAS e MORAL (2001) o aumento do $\mathrm{pH}$ no líquido de cobertura poderia ser decorrente do extravasamento de material nitrogenado do músculo para esse meio.

Entre 30 e 90 dias de armazenamento verificou-se aumento nos valores de $\mathrm{pH}$ das conservas avaliadas. VERGARA et al. (2003) e GOULAS e KONTOMINAS (2005) relataram que o tempo de armazenamento pode causar diferenças no $\mathrm{pH}$ de produtos cárneos. A decomposição de compostos nitrogenados, como amônia, tende a elevar o valor do pH (SIKORSKI, KOLAKOWSKA e BURT, 1994; RUIZ-CAPILLAS e MORAL, 2001) muitas vezes indicando perda da qualidade do produto (GÖKOLU, CENGIZ e YERLIKAYA, 2004). Com exceção da conserva 3 aos 30, 60 e 90 dias de armazenamento, e das conservas 1 e 2 aos 90 dias de armazenamento, todas as demais apresentaram valores ideais de pH. GOULD (1996) recomendou pH menor que 4,3 e 4, 5 para limitar o crescimento microbiano e do 
Clostridium botulinum. Resultados semelhantes foram observados por SIKORSKI, KOLAKOWSKA e BURT (1994), que debitaram a estabilidade do pH em conservas ao efeito tamponante do músculo do pescado. Segundo tais autores, o efeito tamponante é creditado à presença de proteínas solúveis, aminoácidos, amônia e substâncias solúveis de baixa massa molar que mascaram as mudanças nos valores do $\mathrm{pH}$.

Pode-se observar que os teores de $\mathrm{NaCl}$ empregados não influenciaram o comportamento do pH, apesar de GARCÍA-REY et al. (2004) e ZHANG et al. (2005) relatarem que o pH de produtos cárneos pode ser afetado pela difusão do $\mathrm{NaCl}$ na fase aquosa do músculo e pela capacidade de retenção de água. Segundo RUIZ-CAPILLAS e MORAL (2001) comportamentos diferenciados podem ocorrer quando são utilizadas espécies diferentes de pescado. Mesmo assim, PASTORIZA et al. (1998) recomendam o uso de $\mathrm{NaCl}$ associado com embalagens especiais para a diminuição das alterações microbiológicas e físicas de pescados.

\section{TABELA 2 - VALORES DE pH DO LÍQUIDO DE COBERTURA, SEM A ADIÇÃO DO MEXILHÃO (A), APÓS 30 MINUTOS DA INCORPORAÇÃO DOS MEXILHÕES, ANTES DO TRATAMENTO TÉRMICO (B), E DAS CONSERVAS COM 30, 60 E 90 DIAS DE ARMAZENAGEM, MANTIDAS EM TEMPERATURA DE $25 \pm 1^{\circ} \mathrm{C}$}

\begin{tabular}{|c|c|c|c|c|c|}
\hline \multirow[t]{2}{*}{ Cons ervas } & \multicolumn{5}{|c|}{$\mathrm{pH}$} \\
\hline & A & B & 30 dias & 60 dias & 90 dias \\
\hline $\begin{array}{l}1 \\
2 \\
3 \\
4 \\
5 \\
6 \\
7 \\
9\end{array}$ & $\begin{array}{l}18 \\
18 \\
17 \\
16 \\
16 \\
16 \\
15 \\
19\end{array}$ & $\begin{array}{l}2,5 \\
2,3 \\
2,7 \\
2,3 \\
2,0 \\
19 \\
2,2 \\
19\end{array}$ & $\begin{array}{l}4,3 \\
3,6 \\
5,8 \\
3,6 \\
3,6 \\
3,5 \\
3,2 \\
3,3\end{array}$ & $\begin{array}{l}4,4 \\
4,5 \\
5,8 \\
3,9 \\
3,9 \\
3,7 \\
3,4 \\
3,4\end{array}$ & $\begin{array}{l}4,6 \\
4,9 \\
4,8 \\
4,0 \\
4,3 \\
4,3 \\
3,8 \\
3,8\end{array}$ \\
\hline
\end{tabular}

RUIZ-CAPILLAS e MORAL (2001), SCHERER et al. (2004) e MANOUSARIDIS et al. (2005) afirmaram que os teores de N-BVT, assim como o $\mathrm{pH}$, indicam a qualidade do pescado. KYRANA $\mathrm{e}$ LOUGOVOIS (2002) atribuem o baixo teor de N-BVT em pescados também à qualidade microbiológica encontrada. SIMÕES et al. (1998) afirmaram que o uso dos teores de N-BVT como indicativo das alterações do pescado implica em considerar que ocorre o desdobramento das proteínas do pescado, resultando na formação de produtos de degradação nitrogenados com menor massa molar (tais como, amônia, aminas ou indol).

Todos os teores de N-BVT (Tabela 3), obtidos para as conservas elaboradas e armazenadas em temperatura ambiente $\left(25 \pm 1^{\circ} \mathrm{C}\right)$ por 90 dias, estavam abaixo do limite máximo estipulado pela legislação vigente (BRASIL, 1997) para pescados e derivados (teores menores do que $30 \mathrm{mg}$ e $25 \mathrm{mg}$ de N-BVT/100 g do produto, respectivamente). Também ficaram abaixo dos teores determinados por KYRANA e LOUGOVOIS (2002). GÖKOLU, CENGIZ e YERLIKAYA (2004) encontraram resultados similares, com aumento nos teores de N-BVT de 8,3 mg/100 g para 15,1 mg N-BVT/100 g em anchovas marinadas em solução de ácido acético a $2 \%$ estocadas por 150 dias. O mesmo comportamento foi verificado por JESUS, LESSI e TENUTA-FILHO (2001) para peixes amazônicos armazenados a -18 e $-36^{\circ} \mathrm{C}$ por 150 dias. 
Os teores de N-BVT indicam que não houve grande liberação de amônia e outras aminas voláteis decorrentes de danos no tecido muscular (mesmo nas conservas que apresentaram os maiores resultados de $\mathrm{pH}$ ), evidenciando bom estado de conservação. Comportamentos semelhantes foram observados por CASTRO et al. (2006).

\subsection{ANÁLISE FÍSICA}

As médias dos valores de textura medidos instrumentalmente (TPA) para as conservas de mexilhões com 30 e 90 dias de armazenamento estão apresentadas nas Tabelas 4 e 5, respectivamente. Pode-se observar na Tabela 4 que somente as conservas 4 a 9 foram avaliadas, pois as conservas $1 \mathrm{a}$ 3 apresentaram resultados de $\mathrm{pH}$ acima do recomendado.

\section{TABELA 3 - TEORES DE NITROGÊNIO DAS BASES VOLÁTEIS TOTAIS (N-BVT) DAS CONSERVAS DE MEXILHÕES ARMAZENADAS DURANTE 90 DIAS}

\begin{tabular}{cc}
\hline Conservas & N-BVT $(\mathbf{m g} / \mathbf{1 0 0} \mathbf{g})$ \\
\hline 1 & 11,04 \\
2 & 9,07 \\
3 & 9,93 \\
4 & 9,35 \\
5 & 13,36 \\
6 & 12,80 \\
7 & 11,80 \\
8 & 13,22 \\
9 & 11,57 \\
\hline
\end{tabular}

O teste de compressão para as conservas armazenadas por 30 dias evidenciou que menores teores de sal e maiores teores de ácido lático contribuíram para a obtenção de texturas mais duras e consistentes. Resultados similares foram encontrados por WESTPHALEN, BRIGGS e LONERGAN (2005) em produtos cárneos cozidos. Esses constataram a existência de relação entre o pH e os parâmetros de textura, sendo a textura desses produtos altamente dependente da gelatinização das proteínas miofibrilares. Já THORARINSDOTTIR et al. (2002) verificaram que a concentração de sal afeta a estabilidade e a desnaturação das proteínas, podendo interferir nos fatores físicos além dos químicos. O teste de penetração indicou que os teores de sal e ácido lático utilizados não influenciaram o parâmetro dureza, porém mexilhões menos consistentes foram encontrados quando se utilizou maiores teores de ácido lático. KILINC e CAKLI (2004) afirmaram que maiores teores de sal e ácido, enquadrados nos limites permitidos, justificariam a grande aceitabilidade sensorial de produtos marinhos marinados. Para as conservas armazenadas por 90 dias em temperatura ambiente, os resultados do teste de compressão revelaram que quanto maior o teor de ácido lático menor a dureza e a consistência dos mexilhões. No teste de penetração não se observou relação entre os parâmetros dureza e consistência com os teores de sal e ácido lático. De acordo com BARRETO (1998) a resposta de determinado material à penetração pode ser afetada pela densidade e uniformidade da matriz, já que somente uma região da seção transversal é submetida à penetração. 


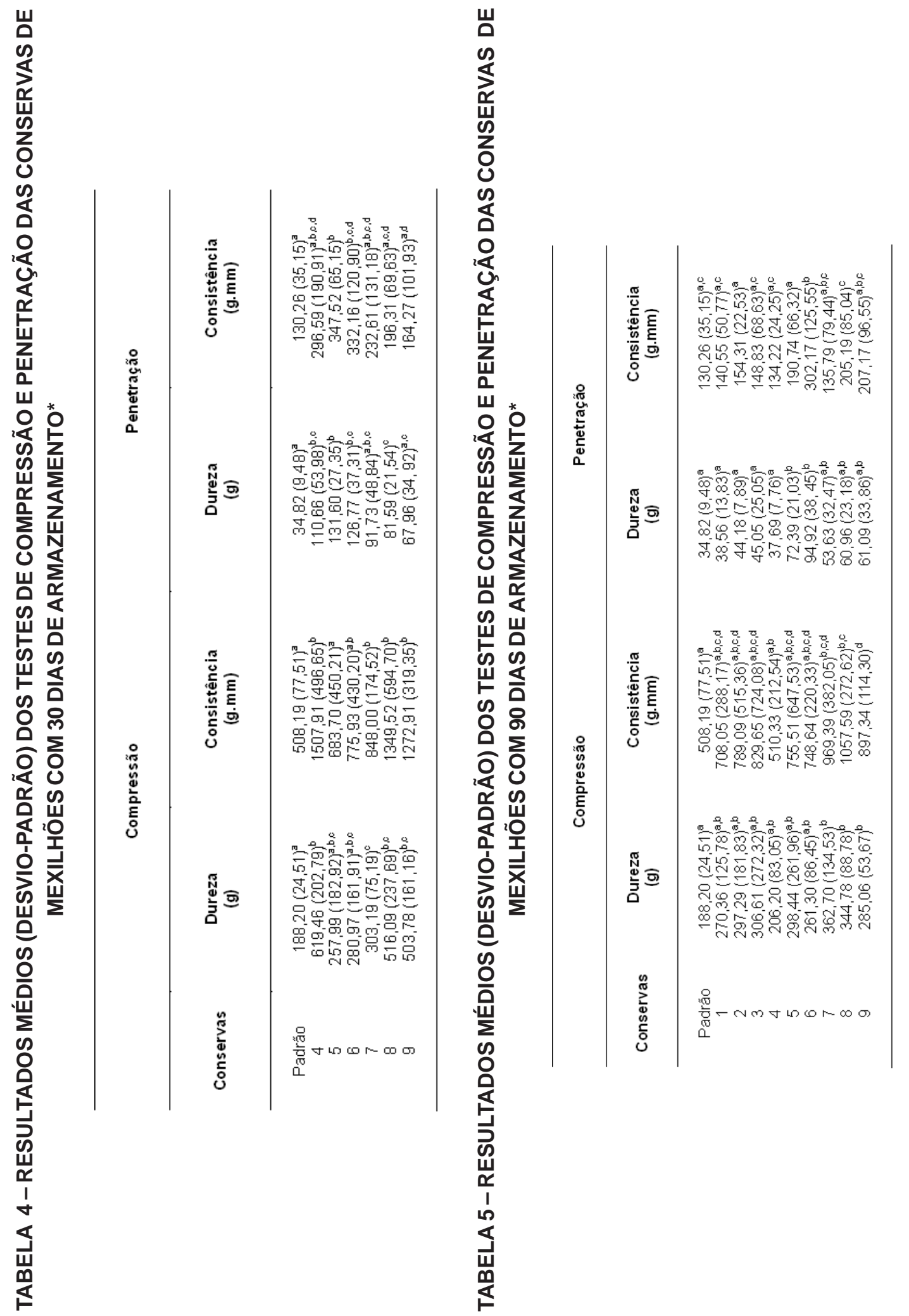

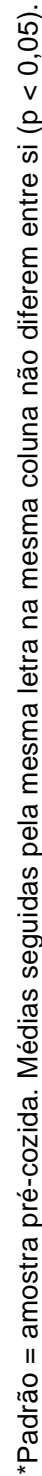




\section{CONCLUSÃO}

Nas condições estudadas neste trabalho existe viabilidade microbiológica, química e física para a produção de conservas de mexilhões (Perna perna) em embalagem flexível a vácuo, armazenadas em temperatura ambiente. O produto é comparável aos mexilhões pré-cozidos, recém preparados, em condições de boas práticas de fabricação.

O teste de compressão indicou que mexilhões em conserva mais duros e consistentes (aos 30 dias de armazenamento) foram obtidos com menores teores de sal e maiores teores de ácido lático. A dureza e a consistência dos mexilhões em conserva armazenados por 90 dias em temperatura ambiente $\left(25 \pm 1^{\circ} \mathrm{C}\right)$ foram inversamente proporcionais à quantidade de ácido láctico empregada. Não foi observada relação dos parâmetros dureza e consistência com os teores de sal e ácido lático empregados no teste de penetração.

\section{ABSTRACT \\ TECHNOLOGICAL, MICROBIOLOGICAL, CHEMICAL AND PHYSICAL EVALUATION OF MUSSEL CONSERVES (Perna perna) VACUUM PACKED}

The aim of this work was evaluate the effect of the thermal processing on vacuum packaging mussel properties, prepared with different content of sodium chloride (salt) and lactic acid, at $25 \pm 1^{\circ} \mathrm{C}$ until 90 days. The product had been evaluated for microbiological characteristics, $\mathrm{pH}$, total volatile base nitrogen (TVB-N) and texture profile. The results obtained for coliforms at $45^{\circ} \mathrm{C}$, Salmonella ssp. and coagulase-positive Staphylococcus were $<3 \mathrm{MPN} / \mathrm{g}$, absence and $<10 \mathrm{CFU} / \mathrm{g}$, respectively. The same behavior was observed for the amount of N-TVB of the conserves that were $\leq 13.36 \mathrm{mg} / 100 \mathrm{~g}$ of the product. Adequate values of $\mathrm{pH}(<4.5)$ had been observed when used amount of lactic acid between 5.0 and $7.5 \%$. Through the compression test it was evidenced higher hardness and consistency of mussel conserves stored per 30 days when used lesser amounts of salt and greater of lactic acid. However, through this exactly test it was verified that in 90 days of storage conserves with lesser hardness and consistency had been observed when used higher amounts of lactic acid. In the penetration test relations between the parameters hardness and consistency had not been observed with the employed amounts of salt and lactic acid.

KEY-WORDS: MUSSELS; MICROBIOLOGY; PHYSICAL-CHEMICAL ANALYSIS; TEXTURE.

\section{REFERÊNCIAS}

1 APHA. American Public Health Association. Compendium of methods of the microbiological examination of foods. 4th ed. Washington D. C., 2001. $676 \mathrm{p}$.

2 AHMED, N. H.; EL SODA, M.; HASSAN, A. N.; FRANK, J. Improving the textural properties of an acidcoagulated (Karish) cheese using exopolysaccharide producing cultures. Lebensmittel-Wissenschaft und-Technologie, v.38, p.843-847, 2005.

3 BARRETO, P. L. M. Estudo histológico, termodinâmico e texturial de surimi obtido de carcaças residuais da filetagem industrial de tilapias (oreochomis 2p) e de sistemas surimi/amido e surimil amido/carragena Florianópolis, 1998. 159 p. Dissertação (Mestrado em Ciência dos Alimentos), Área de Concentração Biotecnologia, Centro de Ciências Agrárias, Universidade Federal de Santa Catarina.

4 BEIRÃO, L. H.; TEIXEIRA, E.; MEINERT, E. M. Processamento e industrialização de moluscos. In: SEMINÁRIO E WORKSHOP TECNOLOGIAS PARA O APROVEITAMENTO INTEGRAL DO PESCADO, Campinas, 22 e 23 de maio de 2000. Livro de resumos... Campinas: ITAL, Centro de Tecnologia da Carne, 2000. p. 38-84.

5 BISPO, E. S.; SANTANA, L. R. R.; CARVALHO, R. D. S.; ANDRADE, G.; LEITE, C. C. Aproveitamento industrial de marisco na produção de lingüiça. Ciência e Tecnologia de Alimentos, v.24, n.4, p.664-668, 2004.

6 BRASIL. Ministério da Agricultura, Pecuária e Abastecimento. Laboratório Nacional de Referência Animal. Métodos analíticos oficiais físico-químicos para controle de pescado e seus derivados. Brasília, 1981. cap. 5. p.1-3. 
7 BRASIL. Ministério da Agricultura, Pecuária e Abastecimento. Portaria n. 185 de 13 de maio de 1997. Regulamento da inspeção industrial e sanitária de produtos de origem animal. Diário Oficial [da] República Federativa do Brasil, Brasília. Disponível em: http://www.agricultura.gov.br. Acesso em: 24 de agosto de 2005.

8 BRASIL. Ministério da Saúde. Agência Nacional de Vigilância Sanitária. Resolução RDC n. 12 de 02 de janeiro de 2001. Regulamento técnico sobre padrões microbiológicos para alimentos. Diário Oficial [da] República Federativa do Brasil, Brasília, 10 de janeiro de 2001. Disponível em: http:// www.anvisa.gov.br. Acesso em: 19 de janeiro de 2005.

9 CASTRO, P.; PADRÓN, J. C. P.; CANSINO, M. J. C.; VELÁZQUEZ, E. S.; LARRIVA, R. M. Total volatile base nitrogen and its use to assess freshness in European sea bass stored in ice. Food Control, v.17, n.4, p.245-248, 2006.

10 CORDEIRO, D. Qualidade do mexilhão (Perna perna) submetido ao processo combinado de cocção, congelamento e armazenamento. Campinas, 2005. 68 f. Dissertação (Mestrado em Ciência e Tecnologia de Alimentos), Escola Superior de Agricultura, Universidade de São Paulo.

11 FRANCO, J. L.; TRIVELLA, D. B. B.; TREVISAN, R.; DINSLAKEN, D. F.; MARQUES, M. R. F.; BAINY, A. C. C.; DAFRE, A. L. Antioxidant status and stress proteins in the gills of the Brown mussel Perna perna exposed to zinc. Chemico-Biological Interactions, v.160, p.232-240, 2006.

12 GARCÍA-REY, R. M.; GARCÍA-GARRIDO, J. A.; QUILES-ZAFRA, R.; TAPIADOR, J.; CASTRO, M. D. L. Relationship between $\mathrm{pH}$ before salting and dry-cured ham quality. Meat Science, v.67, n.4, p.625-632, 2004.

13 GÖKOLU, N.; CENGIZ, E.; YERLIKAYA, P. Determination of the shelf life of marinated sardine (Sardina pilchardus) stored at $4^{\circ} \mathrm{C}$. Food Control, v.15, n.1, p.1-4, 2004.

14 GOMES, Frederico Pimentel. Curso de estatística experimental. 13. ed. São Paulo: Nobel, 1990. 468 p.

15 GOULD, G. W. Methods for preservation and extension of shelf life. International Journal of Food Microbiology, v.33, n.1, p.51-64, 1996.

16 GOULAS, A. E.; KONTOMINAS, M. G. Effect of salting and smoking-method on the keeping quality of chub mackerel (Scomber japonicus): biochemical and sensory attributes. Food Chemistry, v.92, n.3, p.511520, 2005.

17 HUBER, E.; SOARES, L. P.; LAURINDO, J. B. Resfriamento a vácuo de mexilhões pré-cozidos para produção em pequena escala. Alimentos e Nutrição, v.14, n.2, p.165-170, 2003.

18 HUIDOBRO, F. R.; MIGUEL, E.; BLÁZQUEZ, B.; ONEGA, E. A comparison between two methods (WarnerBratzler and texture profile analysis) for testing either raw meat or cooked meat. Meat Science, v.69, n.3, p.527-536, 2005.

19 JESUS, R. S.; LESSI, E.; TENUTA-FILHO, A. Estabilidade química e microbiológica de "minced fish" de peixes amazônicos durante o congelamento. Ciência e Tecnologia de Alimentos, v.21, n.2, p.144-148, 2001.

20 KILINC, B.; CAKLI, S. Chemical, microbiological and sensory changes in thawed frozen fillets of sardine (Sardina pilchardus) during marination. Food Chemistry, v.88, p.275-280, 2004.

21 KYRANA, V. R.; LOUGOVOIS, V. P. Sensory, chemical and microbiological assessment of farm-raised European sea bass (Dicentrarchus labrax) stored in melting ice. International Journal of Food Science and Technology, v.37, p.319-328, 2002.

22 LIZÁRRAGA-PARTIDA, M. L.; CÁRDENAS, G. V. Influence of water circulation on marine and faecal bactéria in a mussel-growing area. Marine Pollution Bulletin, v.32, n.2, p.196-201, 1996.

23 MARENZI, A. W. C.; BRANCO, J. O. O mexilhão Perna perna (Linnaeus) (Bivalvia, Mytilidae) em cultivo na Armação do Itapocoroy, Santa Catarina, Brasil. Revista Brasileira de Zoologia, v.22, n.2, p.394-399, 2005.

24 MARQUES, H. L. A. Criação comercial de mexilhões. São Paulo: Nobel, 1998. 83 p.

25 MANOURSARIDIS, G.; NERANTZAKI, A.; PALEOLOGOS, E. K.; TSIOTSIAS, A.; SAVVAIDIS, I. N.; KONTOMINAS, M. G. Effect of ozone on microbial, chemical and sensory attributes of shucked mussels. Food Microbiology, v. 22, p. 1-9, 2005. 
26 NEIVA, C. R. P. Valor agregado x qualidade do pescado. Disponível em: http://www.pesca.sp.gov.br/ textos.php. Acesso em: 05 fev. 2004.

27 PACHECO, D. Brasil investe no futuro da aqüicultura e pesca. Revista Nacional da Carne, v.28, n.236, p.18-23, 2004.

28 PASTORIZA, L.; SAMPEDRO, G.; HERRERA, J. J.; CABO, L. M. Influence of sodium chloride and modified atmosphere packaging on microbiological, chemical and sensorial properties in ice storage of slices of hake (Merluccius merluccius). Food Chemistry, v.61, n.1-2, p.23-28, 1998.

29 PEREIRA, C. S.; POSSAS, C. A.; VIANA, C. M.; RODRIGUES, D. P. Aeromonas spp. e Plesiomonas shigelloides isoladas a partir de mexilhões (Perna perna) in natura e pré-cozidos no Rio de Janeiro, RJ. Ciência e Tecnologia de Alimentos, v.24, n.4, p.562-566, 2004.

30 RUIZ-CAPILLAS, C.; MORAL, A. Correlation between biochemical and sensory quality indices in hake stored in ice. Food Research International, v.34, n.5, p.441-447, 2001.

31 SANTOS, E. Moluscos no Brasil: vida e costumes. Belo Horizonte: Itatiaia, 1982. p.40-65.

32 SAS INSTITUTE INC. System for Microsoft Windows. Release 6.12. Cary, 1996.

33 SCHERER, R.; DANIEL, A. P.; AUGUST, P. R.; LAZZARI, R.; LIMA, R. L.; FRIES, L. L. M.; RADUNZ NETO, J.; EMANUELLI, T. Efeito do gelo clorado sobre parâmetros químicos e microbiológicos da carne de carpa capim (Ctnopharyngodon idella). Ciência e Tecnologia de Alimentos, v.24, n.4, p. 680-684, 2004,

34 SIKORSKI, Z. E.; KOLAKOWSKA, A.; BURT, J. R. Cambios bioquimicos e microbianos subsiguientes a la captura. In: SIKORSKI, Z.E. (Ed.). Tecnologia de los productos del mar: recursos, composition y conservation. Zaragoza: Acribia, 1994. p.73-101.

35 SIMÕES, D. R. S.; PEDROSO, M. A.; AUGUSTO RUIZ, W.; ALMEIDA, T. L. Hambúrgueres formulados com base protéica de pescado. Ciência e Tecnologia de Alimentos, v.18, n.4, p.410-413, 1998.

36 SOLIC, M.; KRSTULOVIC, N.; JOZIC, S.; CURAC, D. The rate of concentration of faecal coliforms in shellfish under different environmental condition. Environment International, v.25, n.8, p. 991-1000, 1999.

37 THORARINSDOTTIR, K. A.; ARASON, S.; GEIRSDOTTIR, M.; BOGASON, S. G.; KRISTBERGSSON, K. Changes in myofibrillar proteins during processing of salted cod (Gadus morhua) as determined by electrophoresis and differential scanning calorimetry. Food Chemistry, v.77, n.3, p.377-385, 2002.

38 VERGARA, H.; GALLEGO, L.; GARCÍA, A.; LANDETE-CASTILLEJOS, T. Conservation of Cervus elaphus meat in modified atmospheres. Meat Science, v.65, n.2, p.779-783, 2003.

39 WESTPHALEN, A. D.; BRIGGS, J. L.; LONERGAN, S. M. Influence of pH on rheological properties of porcine myofibrillar protein during heat induced gelation. Meat Science, v.70, n.2, p.293-299, 2005.

40 WILHELM FILHO, D.; TRIBESS, T.; GÁSPARI, C.; CLAUDIO, F. D.; TORRES, M. A.; MAGALHÃES, A. R. M. Seasonal changes in antioxidant defenses of the digestive gland of the Brown mussel (Perna perna). Aquaculture, v.203, p.149-158, 2001.

41 ZHANG, S. X.; FAROUK, M. M.; YOUNG, O. A.; WIELICZKO, K. J.; PODMORE, C. Functional stability of frozen normal and high pH beef. Meat Science, v.69, n.4, p.765-772, 2005.

\section{AGRADECIMENTOS}

Ao programa Prodetab, Embrapa, pelo apoio financeiro a este trabalho. 
Os teores de N-BVT indicam que não houve grande liberação de amônia e outras aminas voláteis decorrentes de danos no tecido muscular (mesmo nas conservas que apresentaram os maiores resultados de $\mathrm{pH}$ ), evidenciando bom estado de conservação. Comportamentos semelhantes foram observados por CASTRO et al. (2006).

\subsection{ANÁLISE FÍSICA}

As médias dos valores de textura medidos instrumentalmente (TPA) para as conservas de mexilhões com 30 e 90 dias de armazenamento estão apresentadas nas Tabelas 4 e 5, respectivamente. Pode-se observar na Tabela 4 que somente as conservas 4 a 9 foram avaliadas, pois as conservas $1 \mathrm{a}$ 3 apresentaram resultados de $\mathrm{pH}$ acima do recomendado.

\section{TABELA 3 - TEORES DE NITROGÊNIO DAS BASES VOLÁTEIS TOTAIS (N-BVT) DAS CONSERVAS DE MEXILHÕES ARMAZENADAS DURANTE 90 DIAS}

\begin{tabular}{cc}
\hline Conservas & N-BVT $(\mathbf{m g} / \mathbf{1 0 0} \mathbf{g})$ \\
\hline 1 & 11,04 \\
2 & 9,07 \\
3 & 9,93 \\
4 & 9,35 \\
5 & 13,36 \\
6 & 12,80 \\
7 & 11,80 \\
8 & 13,22 \\
9 & 11,57 \\
\hline
\end{tabular}

O teste de compressão para as conservas armazenadas por 30 dias evidenciou que menores teores de sal e maiores teores de ácido lático contribuíram para a obtenção de texturas mais duras e consistentes. Resultados similares foram encontrados por WESTPHALEN, BRIGGS e LONERGAN (2005) em produtos cárneos cozidos. Esses constataram a existência de relação entre o pH e os parâmetros de textura, sendo a textura desses produtos altamente dependente da gelatinização das proteínas miofibrilares. Já THORARINSDOTTIR et al. (2002) verificaram que a concentração de sal afeta a estabilidade e a desnaturação das proteínas, podendo interferir nos fatores físicos além dos químicos. O teste de penetração indicou que os teores de sal e ácido lático utilizados não influenciaram o parâmetro dureza, porém mexilhões menos consistentes foram encontrados quando se utilizou maiores teores de ácido lático. KILINC e CAKLI (2004) afirmaram que maiores teores de sal e ácido, enquadrados nos limites permitidos, justificariam a grande aceitabilidade sensorial de produtos marinhos marinados. Para as conservas armazenadas por 90 dias em temperatura ambiente, os resultados do teste de compressão revelaram que quanto maior o teor de ácido lático menor a dureza e a consistência dos mexilhões. No teste de penetração não se observou relação entre os parâmetros dureza e consistência com os teores de sal e ácido lático. De acordo com BARRETO (1998) a resposta de determinado material à penetração pode ser afetada pela densidade e uniformidade da matriz, já que somente uma região da seção transversal é submetida à penetração. 


\section{CONCLUSÃO}

Nas condições estudadas neste trabalho existe viabilidade microbiológica, química e física para a produção de conservas de mexilhões (Perna perna) em embalagem flexível a vácuo, armazenadas em temperatura ambiente. O produto é comparável aos mexilhões pré-cozidos, recém preparados, em condições de boas práticas de fabricação.

O teste de compressão indicou que mexilhões em conserva mais duros e consistentes (aos 30 dias de armazenamento) foram obtidos com menores teores de sal e maiores teores de ácido lático. A dureza e a consistência dos mexilhões em conserva armazenados por 90 dias em temperatura ambiente $\left(25 \pm 1^{\circ} \mathrm{C}\right)$ foram inversamente proporcionais à quantidade de ácido láctico empregada. Não foi observada relação dos parâmetros dureza e consistência com os teores de sal e ácido lático empregados no teste de penetração.

\section{ABSTRACT \\ TECHNOLOGICAL, MICROBIOLOGICAL, CHEMICAL AND PHYSICAL EVALUATION OF MUSSEL CONSERVES (Perna perna) VACUUM PACKED}

The aim of this work was evaluate the effect of the thermal processing on vacuum packaging mussel properties, prepared with different content of sodium chloride (salt) and lactic acid, at $25 \pm 1^{\circ} \mathrm{C}$ until 90 days. The product had been evaluated for microbiological characteristics, $\mathrm{pH}$, total volatile base nitrogen (TVB-N) and texture profile. The results obtained for coliforms at $45^{\circ} \mathrm{C}$, Salmonella ssp. and coagulase-positive Staphylococcus were $<3 \mathrm{MPN} / \mathrm{g}$, absence and $<10 \mathrm{CFU} / \mathrm{g}$, respectively. The same behavior was observed for the amount of N-TVB of the conserves that were $\leq 13.36 \mathrm{mg} / 100 \mathrm{~g}$ of the product. Adequate values of $\mathrm{pH}(<4.5)$ had been observed when used amount of lactic acid between 5.0 and $7.5 \%$. Through the compression test it was evidenced higher hardness and consistency of mussel conserves stored per 30 days when used lesser amounts of salt and greater of lactic acid. However, through this exactly test it was verified that in 90 days of storage conserves with lesser hardness and consistency had been observed when used higher amounts of lactic acid. In the penetration test relations between the parameters hardness and consistency had not been observed with the employed amounts of salt and lactic acid.

KEY-WORDS: MUSSELS; MICROBIOLOGY; PHYSICAL-CHEMICAL ANALYSIS; TEXTURE.

\section{REFERÊNCIAS}

1 APHA. American Public Health Association. Compendium of methods of the microbiological examination of foods. 4th ed. Washington D. C., 2001. $676 \mathrm{p}$.

2 AHMED, N. H.; EL SODA, M.; HASSAN, A. N.; FRANK, J. Improving the textural properties of an acidcoagulated (Karish) cheese using exopolysaccharide producing cultures. Lebensmittel-Wissenschaft und-Technologie, v.38, p.843-847, 2005.

3 BARRETO, P. L. M. Estudo histológico, termodinâmico e texturial de surimi obtido de carcaças residuais da filetagem industrial de tilapias (oreochomis 2p) e de sistemas surimi/amido e surimil amido/carragena Florianópolis, 1998. 159 p. Dissertação (Mestrado em Ciência dos Alimentos), Área de Concentração Biotecnologia, Centro de Ciências Agrárias, Universidade Federal de Santa Catarina.

4 BEIRÃO, L. H.; TEIXEIRA, E.; MEINERT, E. M. Processamento e industrialização de moluscos. In: SEMINÁRIO E WORKSHOP TECNOLOGIAS PARA O APROVEITAMENTO INTEGRAL DO PESCADO, Campinas, 22 e 23 de maio de 2000. Livro de resumos... Campinas: ITAL, Centro de Tecnologia da Carne, 2000. p. 38-84.

5 BISPO, E. S.; SANTANA, L. R. R.; CARVALHO, R. D. S.; ANDRADE, G.; LEITE, C. C. Aproveitamento industrial de marisco na produção de lingüiça. Ciência e Tecnologia de Alimentos, v.24, n.4, p.664-668, 2004.

6 BRASIL. Ministério da Agricultura, Pecuária e Abastecimento. Laboratório Nacional de Referência Animal. Métodos analíticos oficiais físico-químicos para controle de pescado e seus derivados. Brasília, 1981. cap. 5. p.1-3. 
7 BRASIL. Ministério da Agricultura, Pecuária e Abastecimento. Portaria n. 185 de 13 de maio de 1997. Regulamento da inspeção industrial e sanitária de produtos de origem animal. Diário Oficial [da] República Federativa do Brasil, Brasília. Disponível em: http://www.agricultura.gov.br. Acesso em: 24 de agosto de 2005.

8 BRASIL. Ministério da Saúde. Agência Nacional de Vigilância Sanitária. Resolução RDC n. 12 de 02 de janeiro de 2001. Regulamento técnico sobre padrões microbiológicos para alimentos. Diário Oficial [da] República Federativa do Brasil, Brasília, 10 de janeiro de 2001. Disponível em: http:// www.anvisa.gov.br. Acesso em: 19 de janeiro de 2005.

9 CASTRO, P.; PADRÓN, J. C. P.; CANSINO, M. J. C.; VELÁZQUEZ, E. S.; LARRIVA, R. M. Total volatile base nitrogen and its use to assess freshness in European sea bass stored in ice. Food Control, v.17, n.4, p.245-248, 2006.

10 CORDEIRO, D. Qualidade do mexilhão (Perna perna) submetido ao processo combinado de cocção, congelamento e armazenamento. Campinas, 2005. 68 f. Dissertação (Mestrado em Ciência e Tecnologia de Alimentos), Escola Superior de Agricultura, Universidade de São Paulo.

11 FRANCO, J. L.; TRIVELLA, D. B. B.; TREVISAN, R.; DINSLAKEN, D. F.; MARQUES, M. R. F.; BAINY, A. C. C.; DAFRE, A. L. Antioxidant status and stress proteins in the gills of the Brown mussel Perna perna exposed to zinc. Chemico-Biological Interactions, v.160, p.232-240, 2006.

12 GARCÍA-REY, R. M.; GARCÍA-GARRIDO, J. A.; QUILES-ZAFRA, R.; TAPIADOR, J.; CASTRO, M. D. L. Relationship between $\mathrm{pH}$ before salting and dry-cured ham quality. Meat Science, v.67, n.4, p.625-632, 2004.

13 GÖKOLU, N.; CENGIZ, E.; YERLIKAYA, P. Determination of the shelf life of marinated sardine (Sardina pilchardus) stored at $4^{\circ} \mathrm{C}$. Food Control, v.15, n.1, p.1-4, 2004.

14 GOMES, Frederico Pimentel. Curso de estatística experimental. 13. ed. São Paulo: Nobel, 1990. 468 p.

15 GOULD, G. W. Methods for preservation and extension of shelf life. International Journal of Food Microbiology, v.33, n.1, p.51-64, 1996.

16 GOULAS, A. E.; KONTOMINAS, M. G. Effect of salting and smoking-method on the keeping quality of chub mackerel (Scomber japonicus): biochemical and sensory attributes. Food Chemistry, v.92, n.3, p.511520, 2005.

17 HUBER, E.; SOARES, L. P.; LAURINDO, J. B. Resfriamento a vácuo de mexilhões pré-cozidos para produção em pequena escala. Alimentos e Nutrição, v.14, n.2, p.165-170, 2003.

18 HUIDOBRO, F. R.; MIGUEL, E.; BLÁZQUEZ, B.; ONEGA, E. A comparison between two methods (WarnerBratzler and texture profile analysis) for testing either raw meat or cooked meat. Meat Science, v.69, n.3, p.527-536, 2005.

19 JESUS, R. S.; LESSI, E.; TENUTA-FILHO, A. Estabilidade química e microbiológica de "minced fish" de peixes amazônicos durante o congelamento. Ciência e Tecnologia de Alimentos, v.21, n.2, p.144-148, 2001.

20 KILINC, B.; CAKLI, S. Chemical, microbiological and sensory changes in thawed frozen fillets of sardine (Sardina pilchardus) during marination. Food Chemistry, v.88, p.275-280, 2004.

21 KYRANA, V. R.; LOUGOVOIS, V. P. Sensory, chemical and microbiological assessment of farm-raised European sea bass (Dicentrarchus labrax) stored in melting ice. International Journal of Food Science and Technology, v.37, p.319-328, 2002.

22 LIZÁRRAGA-PARTIDA, M. L.; CÁRDENAS, G. V. Influence of water circulation on marine and faecal bactéria in a mussel-growing area. Marine Pollution Bulletin, v.32, n.2, p.196-201, 1996.

23 MARENZI, A. W. C.; BRANCO, J. O. O mexilhão Perna perna (Linnaeus) (Bivalvia, Mytilidae) em cultivo na Armação do Itapocoroy, Santa Catarina, Brasil. Revista Brasileira de Zoologia, v.22, n.2, p.394-399, 2005.

24 MARQUES, H. L. A. Criação comercial de mexilhões. São Paulo: Nobel, 1998. 83 p.

25 MANOURSARIDIS, G.; NERANTZAKI, A.; PALEOLOGOS, E. K.; TSIOTSIAS, A.; SAVVAIDIS, I. N.; KONTOMINAS, M. G. Effect of ozone on microbial, chemical and sensory attributes of shucked mussels. Food Microbiology, v. 22, p. 1-9, 2005. 
26 NEIVA, C. R. P. Valor agregado x qualidade do pescado. Disponível em: http://www.pesca.sp.gov.br/ textos.php. Acesso em: 05 fev. 2004.

27 PACHECO, D. Brasil investe no futuro da aqüicultura e pesca. Revista Nacional da Carne, v.28, n.236, p.18-23, 2004.

28 PASTORIZA, L.; SAMPEDRO, G.; HERRERA, J. J.; CABO, L. M. Influence of sodium chloride and modified atmosphere packaging on microbiological, chemical and sensorial properties in ice storage of slices of hake (Merluccius merluccius). Food Chemistry, v.61, n.1-2, p.23-28, 1998.

29 PEREIRA, C. S.; POSSAS, C. A.; VIANA, C. M.; RODRIGUES, D. P. Aeromonas spp. e Plesiomonas shigelloides isoladas a partir de mexilhões (Perna perna) in natura e pré-cozidos no Rio de Janeiro, RJ. Ciência e Tecnologia de Alimentos, v.24, n.4, p.562-566, 2004.

30 RUIZ-CAPILLAS, C.; MORAL, A. Correlation between biochemical and sensory quality indices in hake stored in ice. Food Research International, v.34, n.5, p.441-447, 2001.

31 SANTOS, E. Moluscos no Brasil: vida e costumes. Belo Horizonte: Itatiaia, 1982. p.40-65.

32 SAS INSTITUTE INC. System for Microsoft Windows. Release 6.12. Cary, 1996.

33 SCHERER, R.; DANIEL, A. P.; AUGUST, P. R.; LAZZARI, R.; LIMA, R. L.; FRIES, L. L. M.; RADUNZ NETO, J.; EMANUELLI, T. Efeito do gelo clorado sobre parâmetros químicos e microbiológicos da carne de carpa capim (Ctnopharyngodon idella). Ciência e Tecnologia de Alimentos, v.24, n.4, p. 680-684, 2004,

34 SIKORSKI, Z. E.; KOLAKOWSKA, A.; BURT, J. R. Cambios bioquimicos e microbianos subsiguientes a la captura. In: SIKORSKI, Z.E. (Ed.). Tecnologia de los productos del mar: recursos, composition y conservation. Zaragoza: Acribia, 1994. p.73-101.

35 SIMÕES, D. R. S.; PEDROSO, M. A.; AUGUSTO RUIZ, W.; ALMEIDA, T. L. Hambúrgueres formulados com base protéica de pescado. Ciência e Tecnologia de Alimentos, v.18, n.4, p.410-413, 1998.

36 SOLIC, M.; KRSTULOVIC, N.; JOZIC, S.; CURAC, D. The rate of concentration of faecal coliforms in shellfish under different environmental condition. Environment International, v.25, n.8, p. 991-1000, 1999.

37 THORARINSDOTTIR, K. A.; ARASON, S.; GEIRSDOTTIR, M.; BOGASON, S. G.; KRISTBERGSSON, K. Changes in myofibrillar proteins during processing of salted cod (Gadus morhua) as determined by electrophoresis and differential scanning calorimetry. Food Chemistry, v.77, n.3, p.377-385, 2002.

38 VERGARA, H.; GALLEGO, L.; GARCÍA, A.; LANDETE-CASTILLEJOS, T. Conservation of Cervus elaphus meat in modified atmospheres. Meat Science, v.65, n.2, p.779-783, 2003.

39 WESTPHALEN, A. D.; BRIGGS, J. L.; LONERGAN, S. M. Influence of pH on rheological properties of porcine myofibrillar protein during heat induced gelation. Meat Science, v.70, n.2, p.293-299, 2005.

40 WILHELM FILHO, D.; TRIBESS, T.; GÁSPARI, C.; CLAUDIO, F. D.; TORRES, M. A.; MAGALHÃES, A. R. M. Seasonal changes in antioxidant defenses of the digestive gland of the Brown mussel (Perna perna). Aquaculture, v.203, p.149-158, 2001.

41 ZHANG, S. X.; FAROUK, M. M.; YOUNG, O. A.; WIELICZKO, K. J.; PODMORE, C. Functional stability of frozen normal and high pH beef. Meat Science, v.69, n.4, p.765-772, 2005.

\section{AGRADECIMENTOS}

Ao programa Prodetab, Embrapa, pelo apoio financeiro a este trabalho. 